УДК 625.017.39

\title{
ЕКСПЕРИМЕНТАЛЬНІ ДОСЛІДЖЕННЯ СТАЛЕБЕТОННИХ КОЛОН ПРИ НАВАНТАЖЕННІ НА ЦЕНТРАЛЬНИЙ СТИСК
}

Канд. техн. наук Ю.В. Глазунов

\section{ЭКСПЕРИМЕНТАЛЬНЫЕ ИССЛЕДОВАНИЯ СТАЛЕБЕТОННЫХ КОЛОНН ПРИ ЦЕНТРАЛЬНОМ СЖАТИИ}

Канд. техн. наук Ю.В. Глазунов

\section{EXPERIMENTAL INVESTIGATION STEEL-CONCRETE COLUMNS ON THE PROCESS OF LONGITUDINAL HAS BEEN DEVELOPED}

Cand. of techn. sciences Y. Glazunov

Подано способи розрахунку сталебетонних колон на ичентральний стиск при передачі поздовжнього навантаження на бетон, на сталь; експериментальні дані про вплив способів передачі поздовжнього навантаження на характер деформування та зруйнування сталебетонних колон, а також вплив сил зчеплення між бетоном $і$ сталлю на несучу здатність сталебетонних колон.

Ключові слова: сталебетон, зовнішнс армування, тензодатчики, бетонне ядро, стальна оболонка, сталебетонний елемент.

Представлены разработанные способы расчета сталебетонных колонн на центральное сжатие при передаче продольной нагрузки на бетон, на сталь; экспериментальные данные о влиянии способов передачи продольной нагрузки на характер деформирования и разрушения сталебетонных колонн; исследования о влиянии сил сцепления между бетоном и сталью на несущую способность сталебетонных колонн.

Ключевые слова: сталебетон, внешнее армирование, тензодатчики, бетонное ядро, стальная оболочка, сталебетонный элемент. 
A method of strength calculation of rectangular section of steel-concrete columns depending on the process of longitudinal loading has been developed. Theoretical and experimental data have been compared. Cite experiment and theoretical investigation steel concrete constructions depending on the process of longitudinal loading has been developed and method their calculation. There was executed the experimental and theoretical researches of the steel-concrete elements, working by center compression.

Keywords: steel-concrete, method their calculation, rectangular section, process of longitudinal loading, have been compared.

Вступ. Основні напрямки прогресу в будівництві належним чином пов'язані із застосуванням ефективних конструкцій. До таких конструкцій належать конструкції із зовнішнім армуванням, зокрема колони, складені з прямокутної обойми, заповненої бетоном.

Бетон у сполученні зі стальною арматурою виявляється основним матеріалом для житлово-громадянського, промислового, енергетичного, транспортного та сільськогосподарського будівництва.

Концентроване розташування листової арматури на зовнішніх гранях сталебетонних конструкцій дозволяє знизити їх масу, зменшити розміри перерізу порівняно із залізобетонними конструкціями та одержати економію сталі при однаковій висоті. Тому поряд 3 пошуками успішно конкуруючих рішень у залізобетоні стимулюється розвиток інших комплексних матеріалів i конструкцій, зокрема сталебетонних.

Економічність конструкцій із зовнішнім армуванням порівняно 3 традиційними залізобетонними забезпечується за рахунок більш раціонального використання матеріалів. Бетон, замкнений в обойму, має збільшену міцність за рахунок бокового стискання; стальна обойма значно захищена від втрати місцевої та загальної стійкості.

Постановка проблеми у загальному вигляді та іï зв'язок із важливими науковими та практичними завданнями. Конструкції із зовнішнім армуванням належать до найбільш ефективних i економічних конструкцій, необхідність упровадження яких у галузі будівництва стає актуальним.

\begin{abstract}
Заміна сталевих конструкцій залізобетонними надає можливість економити сталь, але це не завжди пов'язано 3 економією грошових коштів.
\end{abstract} Тому поряд 3 пошуками успішно конкуруючих рішень у залізобетоні стимулюється розвиток інших комплексних матеріалів i конструкцій, зокрема сталебетонних.

Однак, широке застосування сталебетонних колон стримується через недостатню розробленість способів розрахунку, які повинні відображати особливості зовнішнього поздовжнього навантаження.

Аналіз останніх досліджень i публікацій. У роботах [1-3] зазначено важливість впровадження конструкцій із зовнішнім армуванням як найбільш економічних конструкцій порівняно 3 традиційними залізобетонними. Економічність таких конструкцій забезпечується за рахунок більш раціонального використання матеріалів.

У науковій праці [1] відмічено, що армування бетону зовнішньою оболонкою сприяє підвищенню міцності такого конструктивного елемента, як сталебетон. Досягаються найкращі показники щодо роботи бетону при навантаженні, у результаті чого зменшуються усадочні деформації і підвищується опір бетону дії агресивного середовища.

У роботі [2] надано дослідження фізико-механічних властивостей матеріалів, які знаходяться у складі сталебетонних конструкцій. Показано вплив матеріалів на несучу здатність і деформації сталебетонних елементів. Визначено геометричні характеристики поперечного перерізу 
конструкції із сталебетону. Показано теоретичні рішення для оцінки напруженодеформованого стану згинаючих стержнів 3 урахуванням об'ємного напруженого стану бетонного ядра.

У роботах [3-5] розроблено методику розрахунку сталебетонних елементів прямокутного поперечного перерізу на міцність при осьовому стиску. Показано взаємодію стальної оболонки і бетонного ядра, яке працює в умовах об'ємного напруженого стану зі змінними параметрами деформування. Наведено чисельні розрахунки напруженодеформованого і граничного стану перерізу сталебетонної конструкції.

Визначення мети та задачі дослідження. Метою даного дослідження є визначення впливу способів передачі зовнішнього поздовжнього навантаження на несучу здатність сталебетонних конструкцій.

У наведеному дослідженні необхідно було вирішити такі завдання:

- розробити способи розрахунку сталебетонних конструкцій на центральний стиск при передачі поздовжнього навантаження на кожний конструктивний елемент окремо;
- у результаті проведеного експерименту визначити вплив способів передачі поздовжнього навантаження на характер деформування та зруйнування сталебетонних конструкцій;

- визначити наявність сил зчеплення між бетоном і сталлю та їх вплив на несучу здатність сталебетонних конструкцій;

- перевірити міцність сталебетонних балочних конструкцій при роботі на згин 3 визначенням сил зсуву по площині з'єднання листової арматури і бетону по довжині балки.

Основна частина дослідження. Розглянемо дослідження напруженого стану сталебетонних колон при різних способах передачі поздовжнього навантаження. При визначенні висновку теоретичних залежностей для визначення несучої здатності передбачається таке:

- колона під навантаженням залишається прямою - не піддається поздовжньому вигину;

- бетонне ядро і оболонка зв'язані між собою силами зчеплення в дискретних точках по довжині і перерізу (рис. 1);

- розподіл поздовжніх контактних зусиль по периметру перерізу приймається рівномірним.

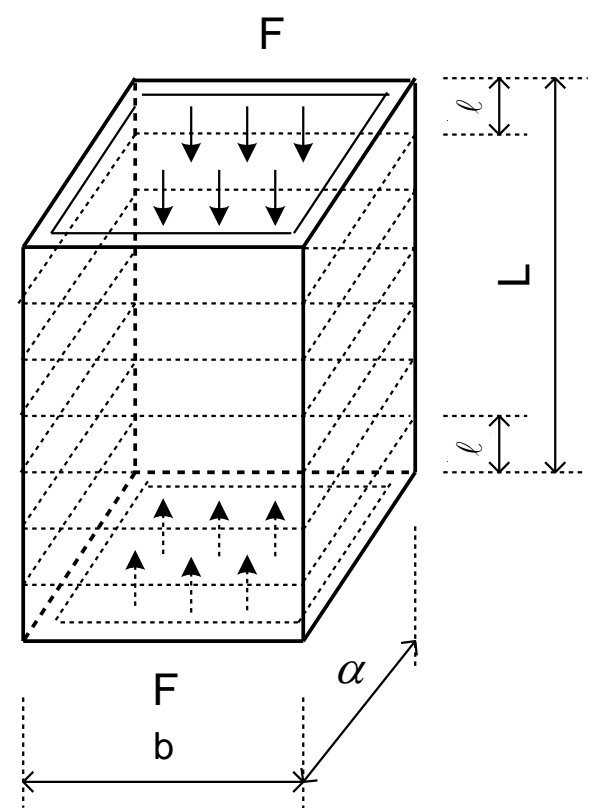

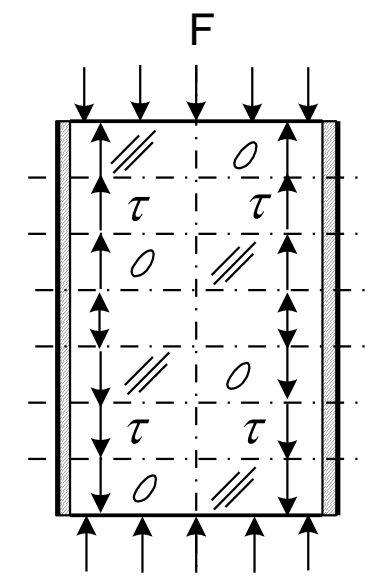

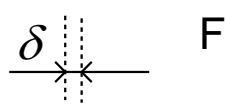

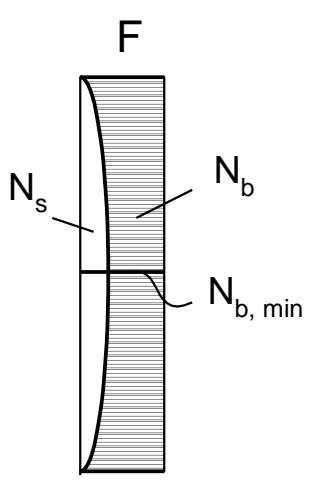

$\mathrm{F}$

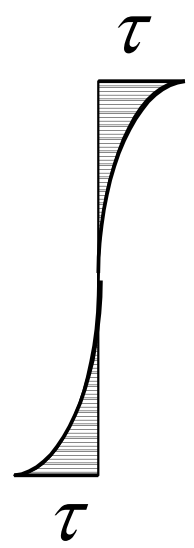

Рис. 1. Навантаження на бетон 
Запишемо умови рівноваги:

$$
\mathrm{N}_{\mathrm{s}}+\mathrm{N}_{\mathrm{c}}=\mathrm{N}_{\mathrm{Ed}}
$$

де $\mathrm{N}_{\mathrm{s}}-$ розрахунковий опір сталевої оболонки за нормального зусилля;

$\mathrm{N}_{\mathrm{c}}$ - розрахункове нормальне зусилля стиску у бетонному ядрі;

$\mathrm{N}_{\mathrm{Ed}}$ - розрахункове значення зовнішньої прикладеної осьової сили.

Умова сумісності деформацій:

$$
\begin{aligned}
\Delta \mathrm{L}_{\mathrm{c}} & =\Delta \mathrm{L}_{\mathrm{s}}, \\
\frac{N_{s} L}{E_{s} A_{s}} & =\frac{N_{c} L}{E_{c} A_{c}},
\end{aligned}
$$

де $\mathrm{E}_{\mathrm{s}}-$ розрахункове значення модуля пружності сталевої оболонки;

$\mathrm{E}_{\mathrm{c}}$ - модуль пружності бетону;

$\mathrm{A}_{\mathrm{s}}$ - площа поперечного перерізу сталевої оболонки;

$\mathrm{A}_{\mathrm{c}}$ - площа поперечного перерізу бетону.

Площа перерізу оболонки:

$$
A_{s}=2 b h+2(b-2 h) h=4 h(b-2 h) .
$$

Площа перерізу бетону:

$$
A_{c}=(b-2 h)^{2} .
$$

Враховуючи вирази (3) і (4) з умови (2) маємо таке значення:

$$
\mathrm{N}_{\mathrm{c}}=\mathrm{N}_{\mathrm{s}} \frac{E_{c}(b-2 h)}{4 h E_{s}} .
$$

Зміна розмірів при поперечній деформації

$$
\varepsilon_{\mathrm{c}}^{\prime}=v_{\mathrm{c}} \varepsilon_{\mathrm{c}}, \quad \varepsilon_{\mathrm{a}}^{\prime}=v_{\mathrm{a}} \varepsilon_{\mathrm{a}}
$$

Враховуючи, що $\varepsilon_{\mathrm{c}}=\varepsilon_{\mathrm{a}}$, а $v_{\mathrm{c}}<v_{\mathrm{a}}$, то $\varepsilon_{\mathrm{c}}^{\prime}<\varepsilon_{\mathrm{a}}^{\prime}$

де $\varepsilon_{\mathrm{c}}-$ значення відносних деформацій стиску бетону;

$\varepsilon_{\mathrm{a}}-$ значення відносних деформацій розтягу конструкційної сталі;

v - коефіцієнт Пуассона.

Розмір поперечного перерізу бетону після деформації (рис. 1) визначається так:

$$
\mathrm{b}_{\mathrm{c}}^{\prime}=\mathrm{b}_{\mathrm{c}} \cdot \varepsilon_{\mathrm{c}}^{\prime}=\mathrm{b}_{\mathrm{c}} \mathrm{v}_{\mathrm{c}} \varepsilon_{\mathrm{c}}=\mathrm{b}_{\mathrm{c}} \mathrm{v}_{\mathrm{c}} \frac{N_{c}}{E_{c} A_{c}}=\frac{v_{c} N_{c}}{E_{c}} \cdot \frac{b_{c}}{A_{c}}=\frac{v_{c} N_{c}}{E_{c}} \cdot \frac{1}{b-2 h} .
$$

Внутрішній розмір поперечного перерізу оболонки (рис. 2):

$$
\mathrm{B}_{\mathrm{s}}^{\prime}=\mathrm{b}_{\mathrm{c}} \cdot \varepsilon_{\mathrm{au}}^{\prime}=\mathrm{b}_{\mathrm{c}} \mathrm{v} \varepsilon_{\mathrm{au}}=\mathrm{b}_{\mathrm{c}} \mathrm{v}_{\mathrm{s}} \frac{N_{s}}{E_{s} A_{s}}=\frac{v_{s} N_{s}}{E_{s}} \cdot \frac{1}{4 h} .
$$

Сили зчеплення, які припадають на кожну елементарну ділянку $\boldsymbol{\ell}$, визначаються так:

$$
\frac{b_{s}-b_{c}}{2}=\frac{\frac{v_{s} N_{s}}{E_{s}} \cdot \frac{1}{4 h}-\frac{v_{c} N_{c}}{E_{c}} \cdot \frac{1}{b-2 h}}{2}=\frac{v_{s} N_{s}}{E_{s}} \cdot \frac{1}{8 h}-\frac{v_{c} N_{c}}{E_{c}} \cdot \frac{1}{2(b-2 h)} .
$$

Чисельна реалізація виконана на ПЕОМ. На рис. 1 показано епюри розподілу зусиль в обоймі, бетонному ядрі, а також епюри дотичних зусиль по довжині колони.
Для визначення несучої здатності колони при передачі навантаження на бетон знаходимо спочатку несучу здатність ядра в середньому перерізі колони (рис. 1). Розрахункову схему обойми i ядра 
зобразимо у вигляді контактуючих між собою елементів (рис. 3).

Сили взаємодії між ядром і обоймою знайдемо із умови рівності переміщень на
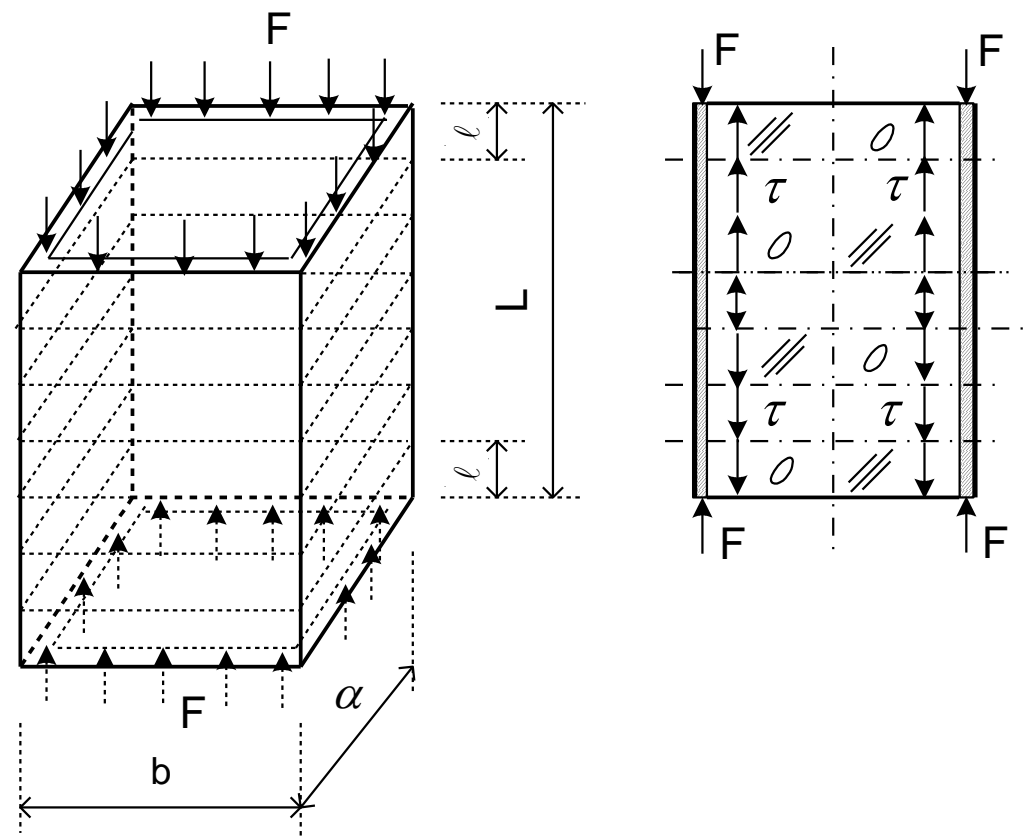

Рис. 2. Навантаження на стальну обойму

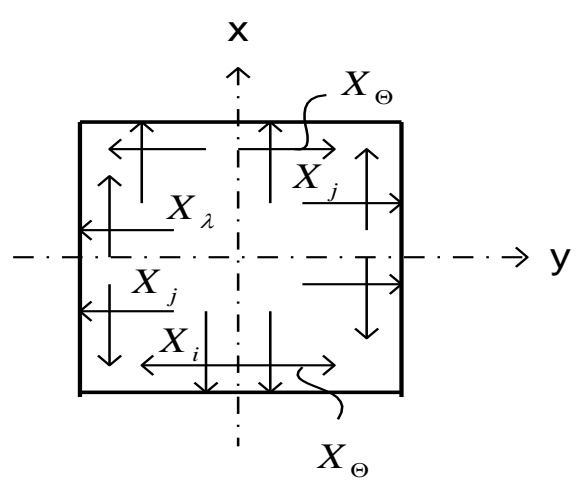

a) границі контакту із такої системи рівнянь:

$$
A \vec{X}=-\vec{H} .
$$

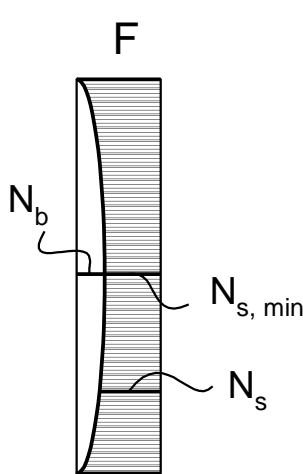

$\mathrm{F}$

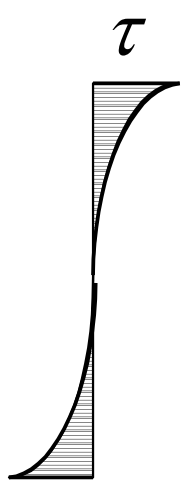

$\tau$ 
обойму як окремі шарнірно оперті пластини, завантажені в поздовжньому i поперечному напрямках. При цьому припускається, що односторонні контактні зв'язки між заповнювачем і обоймою не перешкоджають згину пластин назовні.

У сталебетонних колонах наявність обойми, яка $\epsilon$ опором переміщенню бетону в поперечному напрямку, призводить до збільшення міцності бетону, а наявність заповнювача усередині оболонки збільшує iii стійкість. Бетон i сталь у такому сполученні створюють найбільш сприятливі умови для спільної роботи.

Сталебетонні зразки були випробувані при передачі поздовжнього навантаження на бетон і сталь одночасно за наявності і відсутності сил зчеплення; на бетон; на стальну обойму у зразку, який заповнений бетоном; на одному торці на бетон, на другому - на сталь; на стальну обойму у зразку без бетонного ядра.

У процесі випробувань замірялися поздовжні і поперечні деформації сталевої обойми. Для цього по всьому периметру середнього перерізу у поздовжньому i поперечному напрямках наклеювалися тензодатчики. Показання приладів знімалися при навантаженні до 100 тс через кожні 10 тс завантаження; понад 100 тс через 5 тс.

Порівняльні графіки, які ілюструють несучу здатність сталебетонних колон при передачі навантаження на бетон і сталь одночасно, на бетон, на стальну обойму залежно від відношення сторін їх поперечного перерізу, показані на рис. 4. 3 даного графіка видно, що несуча здатність складених колон значно перевищує суму найбільших зусиль в оболонці і бетонному ядрі, випробуваних окремо.

Результати випробувань стальних обойм у зразках без бетонного ядра показують, що розрахунки критичних напружень i границі несучої здатності надають надмірну, порівняно 3 експериментальними результатами, відносну помилку, яка не перевищує $15 \%$.

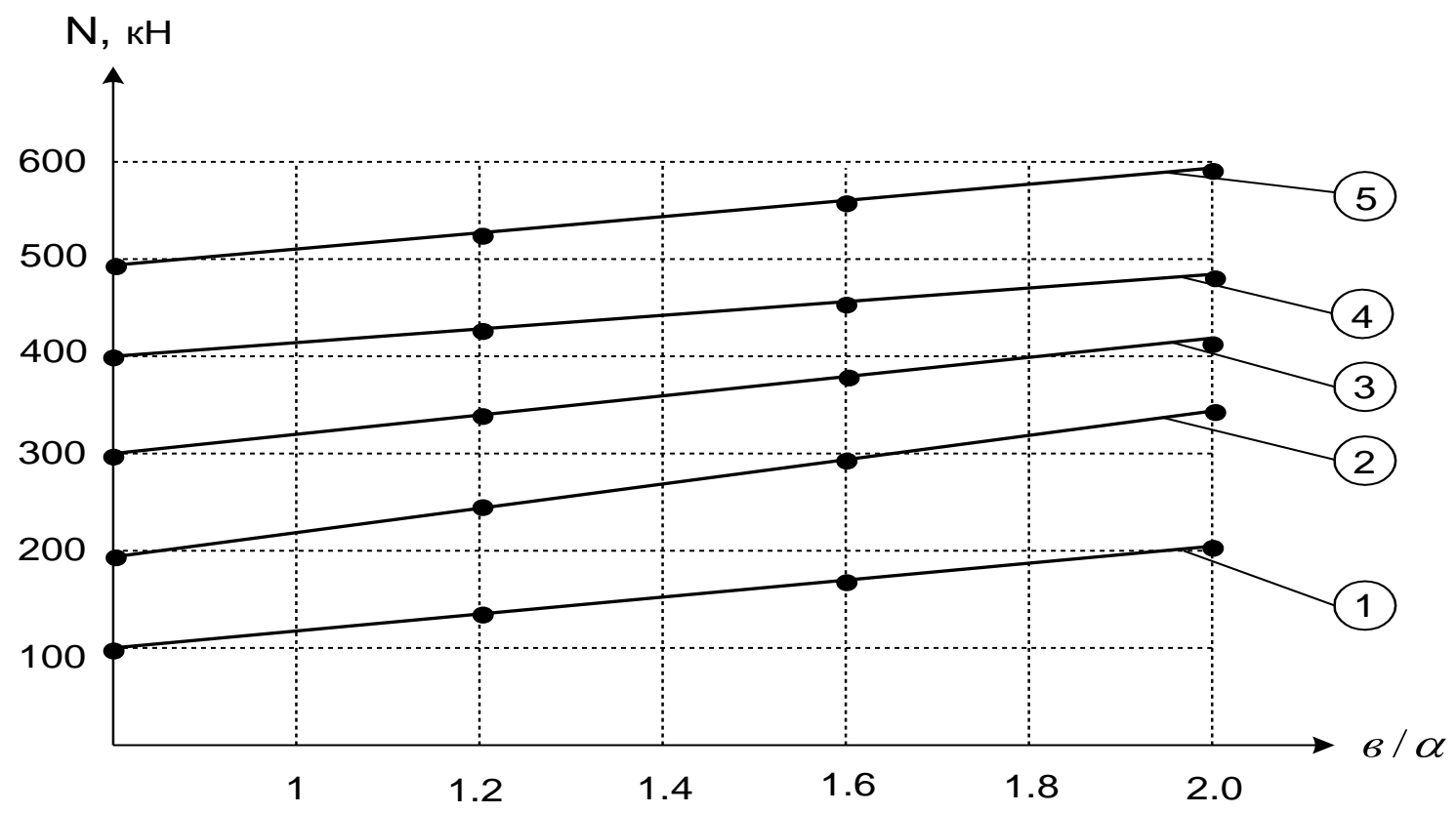

Рис. 4. Графік залежності несучої здатності зразків від розмірів поперечних перерізів $\left(\boldsymbol{\delta}=2 \mathrm{MM} ; \mathrm{f}_{\mathrm{cd}}=25,2 \mathrm{M \Pi а} ; \sigma_{\mathrm{c}}=350 \mathrm{M \Pi а}\right):$

1 - навантаження на бетон і сталь одночасно; 2 - навантаження на бетон;

3 - навантаження на обойму; 4 - бетонна колона; 5 - стальна обойма 
Кожний зразок являє собою металеву оболонку, виготовлену із листа СТ-3 товщиною $\boldsymbol{\delta}=3,8$ мм, зігнутого i зварюваного поздовжнім швом. Внутрішня поверхня не була оброблена і залишалась гладкою. Наплавлений метал у зварному шві розташовується із зовнішньої сторони. Оболонки заповнювались бетоном i витримувались у лабораторних умовах при температурі $18-19{ }^{\circ} \mathrm{C}$.

Міцність бетону в кожному зразку, окрім стандартних випробувань, визначалась у результаті випробування бетонних призм, виготовлених у розбірній металевій опалубці, яка повторює внутрішні розміри обойми i контролювалася випробуванням видавленої призми.

Випробування проводились на гідравлічній машині. Зразок установлювався на опірну плиту преса. Навантаження на бетон передавалось через спеціальний пуансон. Зазор між внутрішньою частиною оболонки i пуансоном складає 3 мм. Швидкість прикладення навантаження - 50 кН/хв. У процесі випробувань записувались діаграми “навантаження-переміщення".

$$
\text { У результаті проведених }
$$

експериментальних досліджень у зразках були визначені граничні навантаження, при яких бетонні призми утримувались у металевих оболонках контактними силами зчеплення між сталлю і бетоном. При цьому способі передачі навантаження деформації бетонної призми не виявляли істотного впливу на деформації граничного шару.

Найбільше навантаження на графіку визначалось характерною точкою, після досягнення якої навантаження зменшувалося і бетонна призма починала переміщуватись у металевій оболонці. На ділянці від початку завантаження впритул до досягнення максимального навантаження зв'язок між дотичними напруженнями і деформаціями граничного шару прямолінійне. Процес видавлювання бетонної призми супроводжувався, як правило, підвищенням навантаження над граничним, яке характеризує наявність сил зчеплення в 1,2-3 рази.

Висновки 3 дослідження i перспективи, подалыший розвиток $\mathbf{y}$ даному напрямку. Проведений аналіз одержаних результатів дозволяє зробити такі висновки:

1. Розроблена і експериментально перевірена методика розрахунку сталебетонних колон на центральний стиск при передачі навантаження "на бетон”; "на оболонку”. При цьому передбачається, що бетонне ядро i оболонка пов'язані між собою силами зчеплення дискретно по довжині зразка і його перерізу.

2. При передачі поздовжнього навантаження на бетон несуча здатність сталебетонних колон складає в середньому 0,8 несучої здатності при передачі навантаження одночасно на бетон i оболонку. Порівняння з несучою здатністю бетонних колон показує, що наявність обойми надає можливість збільшити несучу здатність сталебетонних колон у середньому в два рази.

3. Несуча здатність при передачі навантаження на обойму складає в середньому 0,46 несучої здатності при завантаженні бетону і обойми одночасно i перевищує в середньому в 1,9 разу несучу здатність порожніх колон.

4. Результати випробувань сталебетонних колон, у яких відсутнє зчеплення між бетоном і стальною обоймою, на центральний стиск при передачі поздовжнього навантаження на бетон i сталь одночасно показують, що сили зчеплення не виявляють істотного впливу на їх несучу здатність.

Використання в будівництві сталебетонних колон прямокутного перерізу, в основу конструкції яких покладено розроблені способи розрахунків, дозволяє при більших навантаженнях та обмежених розмірах поперечних перерізів знизити витрату сталі на 28-35 \% порівняно із залізобетонними колонами. 


\section{Список використаних джерел}

1. Грушко, И.М. Повышение прочности и выносливости бетона [Текст] / И.М. Грушко, А.Г. Ильин, Э.Д. Чихладзе. - Харьков: Изд-во при Харьковском гос. университете, 1986. $150 \mathrm{c}$.

2. Стороженко, Л.І. Сталезалізобетонні конструкції [Текст] / Л.I. Стороженко, О.В. Семко. - Полтава, 2001. - 55 с.

3. Чихладзе, Э.Д. Расчет сталебетонных элементов прямоугольного сечения на прочность при осевом сжатии [Текст] / Э.Д. Чихладзе, А.Д. Арсланханов // Бетон и железобетон. - 1993. - № 1, - С. 13-15.

4. Лопатто, А.Э. О свойствах бетона, твердеющего в замкнутой обойме, и жесткости трубобетонных элементов [Текст] // Строительные конструкции. - К., 1973 . - С. 232.

5. Глазунов, Ю.В. Вплив способів передачі поздовжнього навантаження на несучу здатність сталебетонних коротких колон прямокутного перерізу [Текст]: автореф. дис.... канд. техн. наук: 05.23.01 / Ю.В. Глазунов. - Харків, 1997. - 22 с.

Рецензент д-р техн. наук, професор А.А. Плугін

Глазунов Юрій Володимирович, кандидат технічних наук, доцент кафедри будівельної механіки та гідравліки Української державної академії залізничного транспорту. Тел.: (057) 730-10-70.E-mail: budmekh@ukr.net.

Glazunov Yuri, cand. techn. sciences, associate professor Department of structural mechanics and hydraulics Ukrainian State Academy of Railway Transport. Tel.: (057) 730-10-70. E-mail: budmekh@ukr.net. 